\title{
Effects of the Word Presentation Modes on English Foreign Language Vocabulary Acquisition
}

\author{
Wang Mi \\ Department of Foreign Languages, China West Normal University, \\ Nanchong, Sichuan Province, China
}

\begin{abstract}
Vocabulary is an essential part of every language not only foreign language. The way teachers teach new vocabulary is vocabulary presentation mode, which influence students' vocabulary retention greatly. According to the cognitive psychology, the way to understand new information varies with the presentation modes of information, which means only with the appropriate presentation modes, the vocabulary acquisition can be facilitated. There are three different presentation modes as follows: vocabulary list, picture mode and incidental context. However, higher rate of forgetting and a single method exist among the senior high students nationwide. Therefore, it is necessary to explore some effective presentation modes to improve senior high school students' vocabulary retention effect. This paper aims to elaborate the effects of different vocabulary presentation modes on students'foreign vocabulary acquisition and retention. This will help students to be familiar with the vocabulary presentation modes so that they can learn the new words efficiently. Some former researchers indicated that there were no significant difference between the three modes on students'vocabulary acquisition and short-term recall, while the three modes affected students' long-term vocabulary retention significantly. Altogether, picture mode has great influence on vocabulary recall, but there is no significant difference between vocabulary list and accidental context. Reasons for the results were explained from the perspectives of modal theory. Finally, implications for foreign vocabulary teaching will be discussed.
\end{abstract}

Keywords: vocabulary presentation modes; vocabulary retention; modal theory; information processing theory; vocabulary teaching

\section{INTRODUCTION}

Vocabulary has a significant status in language acquisition. Wilkins (1972) said: "Without grammar, we cannot express ourselves freely; but without vocabulary, we cannot express anything." There is no doubt that vocabulary knowledge is essential for learners' foreign language ability. However, the problem existing with Foreign Language Learning is that learners are not able to increase their vocabulary size efficiently, which demands a better method to improve the foreign vocabulary acquisition. This chapter presents a brief introduction of background information and significance of this study.

\subsection{Background Information}

Vocabulary is one of the three core elements of a language. In EFT, there have been contrasts towards the role of vocabulary. Some scholars hold that foreign language learning is completely based on text structures and syntax, thus it is not necessary to learn vocabulary. While other researchers believe that the process of learning English is actually the process of learning vocabulary and grammar, adequate vocabulary and grammar ensures students to master more language.

This study intends to compare the effects of different presentation modes in English Foreign Language vocabulary teaching. Vocabulary acquisition, important as it is, has received more attention in the international research agenda (Lawson \& Hogben, 1996; Nation, 1993, 2001). According to some studies, the larger vocabulary learners master, the higher ability in English they have (He, 1998; Liang, 2006). We can say that vocabulary size is a reflection of how educated a person is. Hence scholars at home and abroad have made a large amount of research on vocabulary acquisition.

\subsection{Significance of this Study}

Vocabulary has been occupying a significant place in language learning for a long time. Some scholars (Laufer, 1991; Meara, 1984; Mc Carthy, 1990) have discussed the importance of vocabulary 
in foreign language acquisition. According to them, vocabulary is regarded as the foundation of listening, speaking, reading and writing. Mc Carthy (1990) said: "even if the learners have mastered the grammar quite successfully and flexibly, and even if they can pronounce the words like the native speakers, without knowing the words, they cannot use a foreign or second language to communicate with others in a meaningful way." So, vocabulary learning should be given the priority in the process of learning a language.

However, the present vocabulary learning and teaching still pose great challenges to foreign language teachers and learners alike. This demands teachers to adopt a more efficient method to teach vocabulary. Therefore, the present study is of great significance to vocabulary learning and teaching.

\subsection{The Current Situation of Vocabulary Teaching in Senior High Students}

As beginners of Foreign Language Learning, senior high students find it difficult to memorize new words and enlarge their vocabulary. It becomes an obstacle for their foreign language learning. Nowadays, vocabulary learning and teaching in junior high school is not satisfactory (Yin, 2007). According to Yin's study, teachers teach students pronunciation and word lists at the beginning of a new lesson. It is obvious that this approach is not beneficial for learners to retain the vocabulary for a long time. In fact, failure to grasp effective approaches to vocabulary learning vocabulary usage, vocabulary memory and at the early stage of learning a foreign language can lead to the reduce of interest and even worse quit the foreign language study.

Moreover, under such situations, learners cannot master the depth of vocabulary well. There are more than fifty new words in each chapter of textbooks. How can learners master the usage of the words by such kind of vocabulary teaching approach during a fifty minutes class? After class, some students memorize new words only through writing and reciting them again and again. Few of them learn new words through connecting new words with the known knowledge. They have no consciousness of learning words according to the inflections of words. Most of them believe the current vocabulary teaching method is not good enough for them to acquire the new words, especially the usage of the words. The analysis of current vocabulary teaching indicates the importance and necessity of foreign vocabulary teaching.

\subsection{Structure of this Paper}

This course paper consists of four chapters altogether.

Chapter one gives a brief introduction of the background, the significance, and the current situation of the vocabulary presentation modes.

Chapter two firstly introduces the definition of vocabulary presentation modes and then some classifications of vocabulary presentation modes will be presented. Finally, the relevant studies abroad and at home will be reviewed.

Chapter three mainly discusses the methodologies of this study.

Chapter four displays the major findings as well as the implications of this study and suggestions for further related research are put forth.

\section{LITERATURE REVIEW}

The research on presentation modes of vocabulary began at the 1960s. In this part, some research works and findings of vocabulary presentation modes at home and abroad will be introduced, which mainly involved the three presentation modes namely; vocabulary list, picture mode and incidental context. Furthermore, some experiments were employed on most occasions and different conclusions were usually made.

\subsection{Definition of Vocabulary Presentation}

The definition of presentation in the Oxford English Dictionary is: "the manner or style in which something is given, offered, or displayed." And "presentation", the first stage in language teaching, is defined as "the introduction of new items, when their meanings are explained, demonstrated, etc., and other necessary information is given" (Longman Dictionary of Language Teaching \& Applied Linguistics, 2002). It is commonly acknowledged that presentation is the first stage in language teaching, during which new vocabulary items, meanings and necessary information are introduced. In foreign language vocabulary teaching, presentation is the procedure of introducing the target vocabulary items to be learnt. 
Mode of word presentation is one of the critical factors which affects vocabulary acquisition which has been neglected for a long time. The goal of vocabulary presentation is as follows: Firstly, the target words are shown to learners which are called learning task assigning; Next, if the teacher uses certain presentation methods effectively, and the learners' perceptual impression of the target words can be deepened. When the learners go into this stage, they will have a long-term memory. Altogether, vocabulary presentation is a process during which appropriate modes to be used to introduce new vocabularies to learners.

\subsection{Classifications of Vocabulary Presentation}

Wu Xia, Wang Qiang and Zhang Ye list the most popular vocabulary learning approach among the students and teachers by analyzing and doing some researches. The favorable approaches are drill practice, association, guessing, context and semantic classification. He Jianing put forward three vocabulary presentation modes of vocabulary list, semantic field and context.

Gaim \& Redman's book working with Words: A guide to teaching and learning vocabulary (1986) once said that there are three kinds of traditional approaches and techniques mentioned to present the vocabulary items, that is, verbal techniques, visual techniques, and audio techniques. Verbal presentation techniques such as definition, translation, or exampling; visual techniques such as the use of pictures, body actions, video or handouts; and audio techniques such as having learners listen to a tape-recording.

\subsubsection{Vocabulary list}

The vocabulary lists is divided into three parts according to the sequence of alphabets. Presentation of vocabulary list means to list the target words one by one and provide written definition so that learners will attend to the spelling, part of speech, meaning and collocation of these words. In addition, it supplies contexts at the level of sentences by means of examples to direct learners to extract words.

\subsubsection{Visual presentation}

Visual presentation aims to present the target words with pictures, cartoons or images, so that learners will attend to the spelling, the meanings of the words, parts of speech and use more materials to activate the schema in their' brains. Visual techniques include photographs, flashcards, wall charts, blackboard drawings, mime, gesture, etc. Visual techniques for the presentation of new lexical items are suitable for visual memory, which is considered favorable for vocabulary retention. Learners can remember the presented material much more effectively if the targeted items presented by means of visual aids. They help students combine the presented material with the knowledge in their mind meaningfully.

\subsubsection{Context presentation}

Context presentation means you can guess the meaning of the words according to the contexts to acquire the target words. Context can present rich information about a new word.However, Mondrian and Boer (1991) insist that "while context always determines the meaning of a word, it does not necessarily reveal that meaning". Sometimes context can unfortunately be unhelpful in getting learners through the right meaning of new lexicon.

Fischer (1994) compared some approaches of word presentation and insisted that the way of presenting words in context is more effective than that in non-context. William and Nagy (2002): "The importance of context in vocabulary presentation and learning is stated as follows: what a word means on any given occasion is mediated by the many contexts in which it is used, and such contexts provide considerable input from which language users clearly pick up huge amounts of vocabulary knowledge, apart from any explicit vocabulary instruction they may receive". Coady \& Nation (1988): Guessing word meaning in context is also important, which involves skills of interpreting surrounding text, predicting, and testing predictions while reading, which enhance reading skills as a whole.

\subsubsection{Semantic field}

Semantic field presentation is a classification of words according to a certain theme. The semantic field words, refers to "semantic clustering" and lexical sets by some academics, is a set of lexical items. The words, applicable to a conceptual domain, are organized in a number of relationships. Neuner (1992) insists that learning words in a lexical set needs less effort. Many scholars believe that semantic field can facilitate the learning of new words. These researchers assume that the similarity 
between items serves to facilitate the learning task and lets the learner notice the small distinctions between words, which results to a better understanding of the words which to be learned.

\subsection{Studies on Vocabulary Presentation Modes}

This sub-section focuses on the research of foreign vocabulary presentation modes abroad and at home.

\subsubsection{Studies on Vocabulary Presentation Modes Abroad}

Oskarsson (1975) presented Swedish learners of English texts concluding unfamiliar target words in English or Swedish. Later, students were told before that they would be tested on the target words after several days. The study revealed that words presented in bilingual glosses were better recalled than words presented in monolingual glosses. Then, Higa (1983) designed a vocabulary presentation list research and found that words presented by a closely related semantic relation were more difficult to be learned than unrelated words, while the unrelated words had a better influence on a long-term memory. So presenting related words should be reduced.

Tinkham (1997) found that word presentation via means of semantic field was not favorable for vocabulary acquisition; Mondria and Wit-de-Boer (1991) believed that context presentation was not of help to the memorization of words. Kroll and Tokowwicz (2005) studied picture presentation and found that this mode was good for vocabulary acquisition. Hence this research employed Latin Square Design experiment and compared the effects of three presentation modes, such as vocabulary list, pictures/cartoon/image presentation and incidental context, on English Foreign Language vocabulary learning and memorization.

\section{Visual Technique and Verbal Technique}

Gairns \&Redman (1986) argue that the presentation of new vocabulary items can be divided into three categories, namely visual technique, verbal technique and dictionary. Visual technique includes flashcards, photographs, blackboard drawings, wall charts, mime, gesture, etc. Visual technique is helpful especially with vocabulary retention. Learners can remember the presented material far more effectively if it has been presented by means of visual aids. Verbal technique includes using illustrative situations, synonymy, definition, contrasts and opposites.

\section{Context}

Coady \& Nation (1988): "Guessing word meaning in context is also important, which involves skills of interpreting surrounding text, predicting, and testing predictions while reading, which enhance reading skills as a whole". William Nagy (2002): "The importance of context in vocabulary presentation and learning is stated as follows: what a word means on any given occasion is mediated by the many contexts in which it is used, and such contexts provide considerable input from which language users clearly pick up huge amounts of vocabulary knowledge, apart from any explicit vocabulary instruction they may receive".

\section{Ten Ways of Presenting the Meaning of New Words}

Penny Ur (2000) offered 10 ways of presenting the meaning of new vocabulary items: 1) concise definition; 2) detailed description; 3) examples (hyponyms); 4) illustration (picture, object); 5) demonstration (acting, mime); 6) context (story or sentence in which the item occurs); 7) synonyms; 8) opposites (antonyms); 9) translation; 10) associated ideas, collocations. And these ways are often used to present new vocabularies to learners by teachers in the process of vocabulary teaching.

\subsubsection{Researches on Vocabulary Presentation Modes at Home}

Compared with the western studies on vocabulary presentation modes, studies in this field are a little bit of late at home. He Jianing (1998) investigated into vocabulary presentation modes of Chinese students and concluded that wordlist was the most effective mode in terms of vocabulary retention size, while context got the best effect on vocabulary retention rate. Zhang and Wei (2004) did an empirical study on presentation modes and showed that retention was higher when learners make their own example sentences than the sentences provided by teachers. 
Word List and Semantic Field

Word list and semantic field play an essential role in presenting new words in foreign language teaching. He Jianing (1998) believed that the ways of presenting words by using word list and semantic field will be helpful if students want to memorize more words within a short period of time. Zhang Li (2009) revealed that words in semantically unrelated sets will be more helpful for memory than those in semantically related sets.

\section{Guessing}

Wang Ying (2006) made some advice for guessing words meaning from context. She concluded that learners should grasp the basic vocabulary aiming to infer word meaning effectively, and master correct ways for the purpose of making fewer mistakes in guessing word's meaning. Wang Xudong (2009) put forward seven strategies for learning vocabularies in context as using context clues, synonym clues, antonym clues, comparison context clues, affix clues, word association clues and repeated context.

\section{Lexical Chunks}

Some researchers deemed that lexical chunks are the ideal memory model, which can increase the number of words one time and help students keep these words longer in their memory in vocabulary teaching and learning. Pu Jianzhong (2003) put forward some suggestions on teaching lexical chunks. New vocabularies should be presented in context and students should take key context into their consideration when learning these new vocabularies. Later, Yu Xiulian (2008) and Gai Shuhua's (2010) empirical researches pointed out that lexical chunks could help students improve their foreign language proficiency.

\section{THEORETICAL FRAMEWORK}

\subsection{Modal Theory}

Weyers (1999) stressed that when students are involved in visual or video materials, they would improve the skills of understanding target language significantly. Gu (2007) discussed about the multimodal learning and believe that as one of the factors that affected learning, modal referred to the means via which man, with the help of their sense organs, interacted with the outside environments such as people, objects and animals.

The picture presentation in this research had no significant advantage of the receptive knowledge but proved to be superior to the productive knowledge simply because picture could present the visual imagery form that written definition could not. The visual imagery is closely related to concrete nouns.

For example, when the word "generator" was presented by picture, a video in English on the operation principles of generators was played. Compared with the written form (a generator is a machine which produces electricity), the video not only allowed the learners to see the appearance of a generator clearly, but also be aware of its operation principles. There is no doubt that it is more favorable for foreign language learners acquiring the word 'generator'.

\subsection{The Information Processing Theory}

Skehan (1998) put forward the information processing theory which includes input, central processing and output stages. In this model, input and output processing are considered to be significant in the process of information encoding. They belong to cognitive theory. The input processing refers to the inductive cognitive mode and the latter refers to the deductive mode. In the view of Skehan, language acquisition is limited on the operation of information processing system. There are five features concluded by Skehan. Firstly, the information processing system does not have enough resources to process all that was received. Secondly, it tends to be meaning-oriented at input stage. Thirdly, learners encode the information through receiving the rules. Next is that learners should have awareness of the information. At last, the inductive representations can be beneficial for language production.

These features give some implications on foreign language vocabulary acquisition. It is necessary to provide explicit instruction to foreign language learners. Vocabulary acquisition has various syntactic aspects such as synonyms, anatomies and collocation which are not rule-based. Based on this truth, some scholars believed that deeper levels of processing bring about more elaborate and longer lasting. 


\section{CONCLUSIONS AND IMPLICATIONS}

Vocabulary presentation plays a vital role in English vocabulary teaching. Researchers and teachers are interest in it. Therefore, teachers and students should be familiar with the vocabulary presentation modes and make good use of these vocabulary presentation modes in teaching or learning. However, more empirical researches on vocabulary presentation modes are also encouraged to further test whether vocabulary presentation modes are effective or not with the help of students vocabulary retention in China.

Based on the major findings from other scholars, we can draw a conclusion that there is a close relationship between presentation modes and the vocabulary learning and retention effects. Different modes produce different learning and retention effects; All in all, picture mode had most significant positive effect on vocabulary recall and production, but there was no significant difference between vocabulary list and context. Reasons for the results were explained from the perspectives of modal theory for foreign language learning. Finally, implications for foreign language teaching and learning were also being discussed.

There are some implications as follows: learners should be provided useful and sufficient input as much possible. Sufficient processing is helpful for learners to construct their vocabulary knowledge. Therefore, teachers should provide as sufficient examples as possible. Furthermore, the feedback especially their classmates may help them deepen their understanding of target words. Finally, instructors should change their roles of dominators into learners' guides in the process of vocabulary learning and encourage learners to extract the information from the materials.

\section{REFERENCES}

[1] Gairns, Redman. (1986). Working with Words: A guide to teaching and learning vocabulary, Cambridge: Cambridge University Press.

[2] He Jianing. (1998). Empirical researches on effects of vocabulary presentation modes on vocabulary retention. Shandong Foreign Language Teaching Journal, 2,60-63.

[3] Lawson, M. J., \& Hogben, D. (1996). The vocabulary learning strategies of foreign-language students. Language Learning, 46, 101-135.

[4] McCarthy, M. (1990). Vocabulary. Oxford, England: Oxford University Press.

[5] Nation, I. S. P. (2001). Learning vocabulary in another language. Cambridge: Cambridge University Press.

[6] Schmitt Norbert, Vocabulary: Description, Acquisition and Pedagogy, Shanghai Foreign Language Education Press, 2002

[7] Wilkins, D. A. (1972). Linguistics in Language Teaching. London: Edward Arnold.

[8] Zhang Bocheng, An Experimental Study on Presentation Modes in English Vocabulary Teaching and Learning, 2005.

[9] 何家宁. 1998. 词汇呈现方式对词汇记忆影响的实验研究. 山东外语教学(2), 60-63.

[10] 梁昆. 2008. 不同呈现模式对词汇学习效果的影响.硕士学位论文, 广东外语外贸大学.

[11] 王文宇. 观念、策略与英语词汇记忆[J]. 外语教学与研究, 1998(1) : 47-52.

[12] 章柏成,韦汉. 2004. 英语词汇教学的呈现方式研究.外语与外语教学(4).

[13] 张萍. 硕士研究生基础英语和专业英语词汇学习策略研究 [J]. 外语教学与研究, 2001 (06): 442-449. 